\title{
Acompanhamento da Implementação do AEE Colaborativo em São Paulo para a Promoção da Educação Inclusiva
}

\author{
Adriana Gomes da Silva Azevedo, Priscilla Mab Conti Miranda, Priscilla Serafim Maciel \\ Centro de Formação e Acompanhamento à Inclusão
}

\begin{abstract}
Resumo
Atualmente, a Educação Especial Paulistana encontra-se na Perspectiva da Educação Inclusiva nas Escolas Regulares do Município de São Paulo, nesta realidade $\mathrm{o}$ atendimento dos educandos com deficiência é prioritariamente nas salas regulares e com o direito ao Atendimento Educacional Especializado (AEE). O AEE Colaborativo surge ancorado no Decreto 57.379 de 2016 que foi regulamentado pela Portaria $\mathrm{n}^{\circ} 8.764$ do mesmo ano. O AEE Colaborativo é uma ação de corresponsabilidade, que visa planejar, intervir e avaliar conjuntamente, estruturando num único planejamento práxis didáticas e metodológicas, cujo objetivo comum visa a quebra de barreiras a fim de efetivar a plena participação e acesso ao currículo do educando com deficiência. De concepção provinda da Convenção da ONU dos Direitos da Pessoa com Deficiência, na perspectiva em que o educando é reconhecido como único e tem respeitado seu desenvolvimento potencial.

Palavras chave: atendimento educacional especializado, barreiras, colaborativo, educação inclusiva.
\end{abstract}

Abstract
Actually, Special Education Paulistana is in the
Perspective of Inclusive Education in the Regular
Schools of the City hall of São Paulo, in this
reality the attendance of students with disabilities
is primarily in the regular rooms and with the right
to Specialized Educational Assistance (AEE). The
Collaborative EEA is anchored in Decree 57.379
of 2016 which was regulated by Ordinance No.
8,764 of the same year. The AEE Collaborative is
an action of co-responsibility, which aims to plan,
intervene and evaluate together, structuring in a
single planning didactic and methodological
praxis, whose common goal is to break down
barriers in order to effect the full participation and
access to the curriculum of the student with a
disability . From the conception of the UN

Convention on the Rights of Persons with Disabilities, from the point of view of the student being recognized as unique and respecting their potential development.

Key words: specialized educational service, barriers, collaborative, inclusive education

O objetivo desse trabalho pretende analisar e defender a prática do AEE Colaborativo que está em implementação no município de São Paulo a partir das prerrogativas do Decreto 57.379 de 2016 regulamentado pela Portaria $\mathrm{n}^{\circ} 8.764$ do mesmo ano.

Segundo a legislação (Art.23; PORTARIA n ${ }^{\circ} 8.764$, de 23 de dezembro de 2016.) as formas possíveis de Atendimento Educacional Especializado são:

"I- Colaborativo: desenvolvido dentro do turno, articulado com profissionais de todas as áreas do conhecimento, em todos os tempos e espaços educativos, assegurando atendimento das especificidades de cada educando e educanda, expressas no Plano de AEE, por meio de acompanhamento sistemático do PAEE;

II- Contraturno: atendimento às especificidades de cada educando e educanda, expressas no Plano do AEE, no contraturno escolar, realizado pelo PAEE, na própria U.E., em U.E. do entorno ou em Centro de Atendimento Educacional Especializado - CAEE em Instituição de Educação Especial conveniada com a SME (Secretaria Municipal de Educação).

III- Itinerante: dentro do turno, de forma articulada e colaborativa com professores da turma, a Equipe Gestora, o PAAI e demais profissionais, assegurando atendimento às especificidades de cada educando e educanda, expressas no Plano do AEE."

Nos ateremos em discorrer sobre o Atendimento Educacional Especializado na modalidade Colaborativo, como uma possibilidade que atenda às demandas específicas de Unidades Escolares que não possuem as condições para as demais formas de AEE previstas na legislação.

Correspondencia: Adriana Gomes da Silva Azevedo, adriana.gomes.educacao@gmail.com

Selección y peer-review bajo responsabilidad del Comité Organizador del XIV Congreso Internacional Galego-Portugués de Psicopedagogía 
Os dados analisados no presente trabalho trazem exemplos de coensino e reflexões sobre os fatores que podem contribuir com a realidade da escola municipal, pensando estratégias que busquem a garantia de equiparação de aprendizagem pautado no modelo colaborativo, quando o professor da sala comum trabalha em colaboração com o docente da educação especial num combinado de corresponsabilidade.

Segundo Mendes (2007) é preciso considerar que se trata de um grande desafio construir uma escola inclusiva, diante de tantas desigualdades sociais presentes em nossa sociedade. Inferimos que pensar juntos, cada qual dentro de sua expertise, cumprindo seus papéis, em que todos os envolvidos no ambiente escolar e mesmo os especialistas dentro dos combinados descritos no Plano do AEE, possibilite um trabalho colaborativo, visando não apenas o acesso e a permanência, mas também o aprendizado dos alunos com deficiências matriculados nas classes comuns.

De acordo com Souza (2008), para que o professor possa acreditar em seu trabalho, antes de tudo, precisa acreditar nas possibilidades de transformação da pessoa com deficiência e, mais do que isso, acreditar que possa ousar na criação de caminhos que sejam decisivos para tal transformação.

O processo de seleção, estágio (treinamento) e acolhimento do Professor de Atendimento Educacional Especializado, realizado pelas equipes do CEFAI (Centro de Formação e Acompanhamento à Inclusão), parte exatamente dessa premissa, onde busca resgatar na prática docente atuante, requisitos que reforcem o potencial do professor como mediador de um processo de aprendizagem motivador e transformador. Diálogos e reflexões em torno de como o aluno aprende, auxiliam no desenvolvimento de novas possibilidades para a criação de estratégias didáticas que aproximem o objeto de estudo do educando, de maneira que sinta-se afetado e instigado a buscar seu conhecimento, de tal modo que o professor sinta-se motivado constantemente, provocando uma força motriz para o trabalho inclusivo efetivamente aconteça.

Em ordem comparativa e cronológica os documentos que norteiam a educação, apontam diferentes caminhos para a concepção do currículo transversal que perpassa a Educação Epecial: "LDB 9.394/96 em seu capítulo V coloca que a educação dos portadores de necessidades especiais deve se dar de preferência na rede regular de ensino, o que tras uma nova concepção na forma de entender a educação e integração dessas pessoas."

O Documento atual a BNCC (Base Nacional Curricular Comum) conta com duas versões disponibilizadas que não constituem a versão final do documento, elas apontam indícios que possibilitam compreender que há um distanciamento entre planejamento, currículo, avaliação e educação inclusiva, no que se refere às especificidades das pessoas com deficiência e a proposta curricular que contemple a discussão da inclusão escolar. Representando por hora uma visão de Educação Especial com perspectivas de inclusão sem garantias suficientes para a permanência na escola, com qualidade social, dos estudantes com deficiências, TGD e altas habilidades/superdotação, apontando um caminho para tornar o currículo acessível para todos.

Nossa proposta de apresentar a implementação do AEE Colaborativo em algumas escolas da Diretoria Regional de Educação Ipiranga, visa colocar a prática colaborativa como premissa de trabalho em que seja preciso discutir na escola questões relacionadas a tempo de planejamento em comum entre professores da educação especial, intitulado PAEE (Professor de Atendimento Educacional Especializado) e o professor da sala regular, pensando juntos os conteúdos que devem ser incluídos no currículo, de acordo com os documentos institucionais que orientam as práticas, quanto as possíveis adaptações que podem se fazer necessárias, à distribuição de responsabilidades, construção de ferramentas avaliativas, procedimentos de registros, documentação pedagógica que possam traçar o acompanhamento do aprendizado dos alunos com deficiência, seguindo às metas estabelecidas coletivamente no seu Plano de Atendimento Educacional Especializado, que corresponde a um plano descritivo e estratégico individualizado.

Segundo Wood (1998), a proposta colaborativa implica em definição e redefinição do papel dos professores da educação especial, como apoio dos professores da sala regular dentro da classe comum, sem retirar o aluno da sala, como acontece no atendimento do contraturno.

Diante dessa premissa acompanhamos três escolas que iniciaram a proposta de AEE Colaborativo, a fim de descrever o percurso dessas Unidades Educacionais, colhemos as percepções dos professores de atendimento educacional especializado, coordenadores, professores e alunos das escolas.A metodologia do trabalho foi baseada na modalidade da pesquisa-ação-colaborativa, acompanhamos os atendimentos, as entradas das professoras e colhemos relatos dos professores, coordenadores e alunos durante nossas itinerâncias como PAAIs (Professores de Apoio e Acompanhamento à Inclusão).

Como pesquisadoras e PAAIs, levamos ideias e intervenções ao campo da pesquisa causando assim, mediação direta e indireta. Segundo Pereira (1998), a pesquisa que pode causar algum impacto no ambiente e que busca explanar e diagnosticar algum problema prático que se quer melhorar e resolver. Salientamos 
que o estudo atende à necessidade de intervenção e conseqüentemente atende a produção de conhecimento científico na área da educação especial.

Tal proposta metodológica incita que a prática de pesquisa-ação-colaborativa ocorra concomitantemente de maneira habitual na rotina escolar entre a sala regular e a ação do PAEE (Professor do Atendimento Educacional Especializado), de tal forma que ambos o educadores possam dialogar nos momentos de ação formativa, práxis que está entre as atribuições do PAEE junto a equipe docente na qual faz parte, em um papel de articulação e pesquisa constantes diante às necessidades de cada escola.

Durante a pesquisa de campo propomos um questionário estruturado que visava explicitar dentro do cotidiano escolar, como se desenvolve o AEE Colaborativo, quais os benefícios, desafios e possíveis desvantagens dessa modalidade de atendimento, bem como a sua contribuição para a inclusão dos alunos com deficiência.

$\mathrm{Na}$ escola que chamaremos de C. a Professora de Atendimento Educacional Especializado, respondeu ao questionário juntamente com a coordenação pedagógica da Unidade. A unidade escolar ressalta pontos positivos e grandes contribuições do AEE Colaborativo no trabalho pedagógico e nas relações interpessoais entre gestão, professor especialista e professores das salas comuns, como segue:

Vantagens do AEE Colaborativo:

Ampliar os momentos de diálogo e reflexão, que possibilitem além dos registros traçarem estratégias e atendimento seguro para esses alunos, envolvendo a equipe escolar, a família e a saúde.

Ter na unidade o AEE.

Até o momento, não vejo desvantagens, pois depois de doze anos, trabalhando no ensino regular, com os alunos com deficiência, pela primeira vez, estou vivenciando momentos de envolver de forma direta professores, gestão e equipe escolar, por meio de conversas com nossos pares avançados, compartilhando sucessos, angústias, conflitos, saberes e de utilizar na prática as estratégias construídas dentro do processo coletivo, com o objetivo de atender melhor todos os alunos.

Como acontece:

a)Informar aos professores envolvidos, dos horários de entrada em sala de aula, com intervenções, construindo juntos as atividades.

b) Conhecer e observar no aluno, sua comunicação com o mundo, suas habilidades, até o momento, desenvolvidas.

c) Preparar a sala, material utilizado, posicionamento de estagiários e os colegas, seria interessante construir kits, que deverão permanecer na sala. d) Ao estar em sala, observar o conteúdo proposto e buscar contextualizá-lo, com as habilidades já apresentadas pelo aluno.

Contribuição para aprimorar o AEE Colaborativo:

Formação, com experiências já existentes.

Conversar com os pares avançados.

Dar um tempo para que o aluno mostre como trabalhar com ele.

Dar um tempo para que a equipe mostre o que conseguem realizar juntos.

Construir com a equipe um foco de trabalho com cada aluno, ressaltando as habilidades, acima do conteúdo proposto, respeitando sua identidade.

Contribuição do trabalho colaborativo na rede;

Como já disse, no início, dá a visibilidade tão sonhada, por nós professores do AEE, ao aluno.

Acalma à equipe e direciona com relação ao que fazer, ou como fazer, dentro das condições de trabalho que nos são apresentadas.

Proporciona atendimento especializado a todas as escolas, independente de ter espaço ou não.

Traz autonomia ao grupo, sem que o professor de AEE, precise estar presente.

No entanto na Unidade $\mathrm{M}$. em que a presença do professor especialista é algo recente (5 meses) notamos nas observações e pelas respostas trazidas no questionário, que se faz necessário aprofundar os estudos em horários coletivos e reuniões pedagógicas sobre o trabalho com o AEE Colaborativo, diante de algumas dificuldades apresentadas pela equipe escolar, sugerimos e organizaremos formações para juntamente com a professora especialista da escola, que serão realizadas para todos os professores e com a gestão escolar no segundo semestre. Seguem algumas colocações dessa Unidade:

Desvantagens:

Dificuldade em atuar em parceria com o professor regente (planejamento de ações, conjuntas, desconhecimento ou desinteresse, opiniões contrárias e oposições de concepções pedagógicas.

A adaptação do conteúdo exige um conhecimento prévio do que será abordado pelo professor em aula e essa comunicação ainda é difícil, pois nem sempre os professores planejam suas aulas com antecedência o que interfere no seu planejamento.

Na unidade A. a PAEE organizou com a equipe gestora o atendimento colaborativo concomitante com o atendimento da SRM (Sala de Recursos Multifuncionais), como segue o relato dessa experiência que apontam os princípios, as contribuições e os desafios: 


\section{Quais os princípios do AEE colaborativo?}

Possibilitar intervenções específicas, visando melhorar a autonomia do aluno, seja no ambiente escolar, como também na sociedade por meio de estratégias que permita ao aluno ultrapassar as barreiras impostas pela sua deficiência.

Articular com os professores, do ensino regular, as atividades adaptadas, com materiais diversificados, possibilitando a construção da aprendizagem nos sujeitos envolvidos neste processo, ampliando o repertório com recursos lúdicos, facilitando a compreensão do que é proposto.

Quais os principais benefícios desse atendimento no cotidiano escolar?

O fato de poder envolver o professor, que não participa de horário coletivo, seduzindo-o para que o mesmo utilize de todos os recursos e estratégias que levem o nosso aluno a aprender.

É poder refletir junto aos professores, família, funcionários sobre as barreiras que impedem o avanço dos alunos.

Quais os principais desafios para a garantia de um AEE Colaborativo de qualidade?

Fazer com que os professores se disponham a trabalhar de maneira diferenciada, acreditando no que lhe é proposto, avaliando o processo e o percurso, refletindo sobre a sua prática e assim replanejando as suas ações pedagógicas.

Realizar parcerias efetivas com a família, visando à melhoria da autonomia dos alunos.

Ter o retorno dos atendimentos externos a escola $e$ ainda, a continuidade dos encaminhamentos realizados pela Unidade educacional.

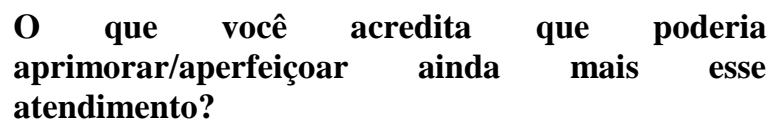

Estratégias pedagógicas mais atrativas e não descontextualizadas do planejamento do professor regente das turmas.

Ter um horário de estudo sistematizado, para o aperfeiçoamento das intervenções propostas para cada aluno, respeitando sempre as respectivas limitações da deficiência de cada criança.

Saber com antecedência o conteúdo do plano de aula do professor regente do ensino regular, para a partir disto garantir uma articulação com o processo de construção do conhecimento do aluno, envolvendo também o professor na efetiva prática.

Ter a possibilidade de atender de maneira flexibilizada, todos os alunos da Unidade Educacional, quando se fizer necessário uma avaliação ou orientação ao professor regente, independente do aluno estar matriculado na SRM.
Nas diferentes experiências o objeto é a garantia dos direitos de aprendizagem preconizados nos documentos institucionais publicados pela Secretaria Municipal de Educação, esses documentos voltados para a construção do currículo, as questões ligadas à educação especial estão diluídas e integradas com os demais componentes curriculares.

Preconizamos o desenvolvimento profissional dos professores, que segundo Marchesi (2010) é condição necessária para que se produzam práticas integradoras positivas nas escolas. Segundo ele, é muito difícil avançar no sentido das escolas inclusivas se os professores, juntamente com os especialistas, não adquirirem uma competência suficiente para ensinar todos os alunos. Acreditamos que os professores devem conhecer, de forma contínua, as possibilidades de aprendizagem dos alunos, os fatores que favorecem, suas habilidades e potencialidades, pautando-se em pesquisas e estudos de casos dentro do momento destinado a formação contínuada de professores que está presente no cotidiano escolar.

De acordo com Blanco (2010), o trabalho do educador competente é ajudar todos os educandos a construir aprendizagens significativas. A construção da aprendizagem significativa implica que "todos os alunos tenham uma pré disposição favorável para aprender, atribuam um sentido pessoal às experiências de aprendizagem e estabeleçam relações substanciais entre as novas aprendizagens e o que já sabem". Mas, para que o professor consiga construir este caminho positivo, segundo Pimenta (2005) ele precisa ser valorizado e visto como agente transformador dos saberes da prática. Reflexão esta, que a prática inclusiva colaborativa pode suscitar na ação coordenadora escolar, reverberando inclusive para a gestão, fato que demanda ação de acompanhamento contínuo do PAAI (Professor de Apoio e Acompanhamento à Inclusão), professor atuante no CEFAI, como aporte para nortear os resultados provindos desta ação docente colaborativa e para a atuação do PAEE (Professor do Atendimento Educacional Especializado).

\section{Referências Bibliográficas:}

Portaria $\mathrm{n}^{\circ}$ 8.764, de 23/12/2016 - Regulamenta O Decreto $\mathrm{N}^{\mathrm{o}}$ 57.379/2016- Institui No Sistema Municipal De Ensino A Política Paulistana De Educação Especial, Na Perspectiva Da Educação Inclusiva.

Azevedo, Maria Antonia R. De; Cunha, Gracilliani R.

Da. Gestão Escolar E Educação Inclusiva: Uma Parceria Necessária E Emergente $\mathrm{Na}$ Escola. Revistaeducação: Teoria E Prática - V. 18, N.31, Jul.-Dez.-2008, P.53-72 
Capellini Vera Lúcia M. F.; Mendes, Enicéia. O Ensino Colaborativo Favorecendo O Desenvolvimento Profissional Para A Inclusão Escolar. In.:Educere Et Educare Revista De Educação, Vol. 2, N. 4, Jul/Dez, 2007, Pp. 113-128. Capellini Vera Lúcia M. F. Construindo Uma Rede De Colaboração: A Importância Da Educação Especial $\mathrm{Na}$ Construção De Uma Escola Inclusiva. Disponível Em: < Http://Www. >Unesp, Bauru. Acesso No Dia: 17/07/2012.

Carvalho, R.E. Removendo Barreiras Para A Aprendizagem - 3a Edição. Porto Alegre: Rs. Editora Mediação, 2003 